\title{
TERAPIAS ALTERNATIVAS/COMPLEMENTARES NO ENSINO PÚBLICO E PRIVADO: ANÁLISE DO CONHECIMENTO DOS ACADÊMICOS DE ENFERMAGEM
}

\author{
Monica Martins Trovo \\ Maria Júlia Paes da Silva² \\ Eliseth Ribeiro Leão ${ }^{3}$
}

Trovo MM, Silva MJP, Leão ER. Terapias alternativas/complementares no ensino público e privado: análise do conhecimento dos acadêmicos de enfermagem. Rev Latino-am Enfermagem 2003 julho-agosto; 11(4):483-9.

Este estudo visou a análise sobre o conhecimento que alunos de graduação em Enfermagem de duas instituições de ensino, uma pública e uma privada, têm em relação às terapias alternativas/complementares, uma vez que ambas as instituições oferecem disciplina específica nessa área, de forma optativa e obrigatória, respectivamente. Os dados encontrados sugerem que o conhecimento sobre o tema decorre do senso comum, além do ensino acadêmico. Os alunos recomendam mais a utilização de terapias alternativas/complementares do que fazem uso das mesmas, sendo as mais conhecidas por eles: a terapia floral, acupuntura, homeopatia, cromoterapia, fitoterapia, musicoterapia e massagem. E o aspecto mais negligenciado no processo ensino-aprendizagem dessa disciplina relaciona-se com os aspectos legais da especialização nesse campo para o enfermeiro.

DESCRITORES: terapias alternativas; terapias complementares; ensino em enfermagem

\section{ALTERNATIVE/COMPLEMENTARY THERAPIES IN PUBLIC AND PRIVATE EDUCATION: A KNOWLEDGE ANALYSIS AMONG NURSING STUDENTS}

This study aimed to analyze undergraduate Nursing students' knowledge in two education institutions, one public and one private, about alternative/complementary therapies, since both institutions offer a specific subject in this area under the optional and obligatory form, respectively. Data suggest that, apart from academic education, knowledge about this theme originates from common sense. The students recommend the use of alternative/complementary therapies although they do not use them much. Flower therapy, acupuncture, homeopathy, cromotherapy, fitotherapy, music therapy and massage are more utilized. The most neglected aspect in the teaching-learning process refers to the legal aspects of specialization in this area for the nurse.

DESCRIPTORS: alternative therapies; complementary therapies; nursing education

\section{TERAPIAS ALTERNATIVAS/COMPLEMENTARES EN LA ENSEÑANZA PÚBLICA Y PRIVADA: UN ANÁLISIS SOBRE EL CONOCIMIENTO DE LOS ALUMNOS DE PREGRADO EN ENFERMERÍA}

Este estudio ha realizado un análisis sobre el conocimiento de los alumnos de pregrado en enfermería de una institución pública y otra privada sobre terapias alternativas/complementarias, una vez que las dos instituciones ofrecen asignatura específica en esta área, de forma optativa y obligatoria respectivamente. Los datos encontrados sugieren que el conocimiento del tema es de uso general además de lo académico. Las terapias alternativas/complementarias más conocidas son: la terapia floral, la acupuntura, la homeopatía, la cromoterapia, la fitoterapia, la musicoterapia y masaje, pero, aunque los alumnos las recomiendan, no las utilizan tanto. El punto más álgido en el proceso de enseñanzal aprendizaje de esta asignatura se refiere a los aspectos legales de la especialización en este campo para el enfermero.

DESCRIPTORES: terapias alternativas; terapias complementarias; educación en enfermería

\footnotetext{
$\overline{1}$ Graduanda do sexto semestre, e-mail: trovomonica@ig.com.br; ${ }^{2}$ Enfermeira, Professor Livre Docente, e-mail: juliaps@usp.br. Escola de Enfermagem da Universidade de São Paulo; ${ }^{3}$ Enfermeira, Doutoranda da Escola de Enfermagem da Universidade de São Paulo, Assessora de Pesquisa Científica do Hospital Samaritano, e-mail: lisleao@uol.com.br
} 
INTRODUÇÃO

A preocupação do homem com o processo saúde-doença não é fato recente. Hipócrates, o pai da medicina, na antiga Grécia, muito antes da era cristã, já definia saúde como o estado de harmonia do homem com a natureza, o equilíbrio entre os diferentes componentes do organismo com o meio ambiente ${ }^{(1)}$. De acordo com seus pensamentos, saúde e doença dependiam de perfeita integração mente/corpo/meio-ambiente.

Esse conceito hipocrático perdurou até a Idade Média, quando os dogmas do catolicismo passaram a responsabilizar o comportamento do homem pelo aparecimento de doenças. De acordo com esse pensamento, a doença era nada mais que um castigo pelos pecados cometidos. O médico perdeu seu papel nesse contexto: a ele cabia apenas o cuidado do corpo, para aliviar o sofrimento.

Com o advento da ciência e o crescimento da cultura ocidental no Renascimento, uma nova forma de pensamento aflorou: o paradigma mecanicista cartesiano passou a ser adotado para explicar o processo saúdedoença.

Segundo esse paradigma, o corpo é composto por partes e visto como máquina, ou seja, todas suas funções dependem do funcionamento independente de cada órgão. Assim sendo, a doença é causada por defeitos das peças da máquina humana. Essa teoria criava uma rigorosa dicotomia entre corpo e mente, cabendo a essa última papel irrelevante ${ }^{(1-2)}$.

No século XX, com as teorias de Einstein, surgiu um novo horizonte: a matéria vista como manifestação de energia e os homens, também formados de matéria, passaram a ser considerados seres energéticos, constituídos de vários sistemas energéticos que interagem entre si e com o meio, formando um todo, que deve sempre estar harmonioso ${ }^{(3)}$. Voltamos assim à antiga concepção hipocrática, porém, acrescentando o espírito à tríade mente/corpo/meio ambiente. Essa visão holística está intimamente ligada com a compreensão da ação das terapias alternativas/complementares ${ }^{(4)}$, também consideradas como medicina tradicional pela Organização Mundial de Saúde ${ }^{(5)}$.

Terapias alternativas/complementares (TAC) são as técnicas que visam à assistência à saúde do indivíduo, seja na prevenção, tratamento ou cura, considerando-o como mente/corpo/espírito e não um conjunto de partes isoladas $^{(6)}$. Seu objetivo, portanto, é diferente daqueles da assistência alopática, também conhecida como medicina ocidental, ou em que a cura da doença deve ocorrer através da intervenção direta no órgão ou parte doente.

Alguns autores ${ }^{(6-7)}$ agrupam as Terapias Alternativas/complementares em:

- terapias físicas - acupuntura, moxabustão, shiatsu (e outras massagens), do-in, argiloterapia, cristais;

- hidroterapia - hidroterapia (não especificada), banhos, vaporização e sauna;

- fitoterapia - fitoterapia (não especificada), ervas medicinais, florais;

- nutrição - nutrição alternativa (não especificada), terapêutica nutricional ortomolecular;

- ondas, radiações e vibrações - radiestesia, radiônica;

- terapias mentais e espirituais - meditação, relaxamento psicomuscular, cromoterapia, toque terapêutico, visualização, Reiki;

- terapia de exercícios individuais - biodança, vitalização.

Há crescente interesse em todo o mundo pela utilização de tais técnicas. Três grandes centros de saúde da cidade de São Paulo já utilizam técnicas como a musicoterapia, o relaxamento/yoga e acupuntura ${ }^{(8)}$. Esse interesse é devido a vários fatores, tais como: o preço elevado da assistência médica privada, associado ao alto custo dos medicamentos, além da precariedade da assistência prestada pelos serviços públicos em geral; verifica-se, na maioria das vezes, que as TAC são tão eficazes como a terapêutica "científica"/aloterapia, além do que, se corretamente utilizadas, não ocasionam efeitos colaterais danosos ao organismo, embora seu mecanismo não esteja totalmente esclarecido. Além disso, há certo ressentimento com a ciência oficial, visto que ela não consegue realizar o sonho de felicidade do ser humano ${ }^{(9)}$.

Há que salientar que a enfermeira exerce papel fundamental nesse contexto já que é ela quem está em contato direto e mais profundo com a população, tendo a oportunidade de educá-la e esclarecê-la quanto ao uso (benéfico ou não) dessas técnicas, seja em hospitais, em centros de saúde ou junto à comunidade ${ }^{(9)}$. O Conselho Federal de Enfermagem (COFEN), no Parecer Informativo 004/95, reconhece a fundamentação da profissão de Enfermagem na visão holística do ser humano, o crescente interesse e utilização das práticas naturais no cuidado ao 
cliente e os aspectos do Código de Ética dos profissionais de Enfermagem que justificam a utilização das terapias naturais ${ }^{(10)}$. Finalmente, em 19/3/1997, o COFEN, através da Resolução 197, estabelece e reconhece as Terapias Alternativas como especialidade e/ou qualificação do profissional de Enfermagem ${ }^{(11)}$. A partir dessa Resolução, o enfermeiro passa a ser reconhecido como terapeuta alternativo/complementar (na área específica), mediante conclusão e aprovação em cursos reconhecidos em instituição de ensino, com carga horária mínima de 360 horas $^{(12)}$.

No Brasil, 47 enfermeiros já atuavam utilizando as TAC no tratamento de seus pacientes em 1993, antes mesmo de seu reconhecimento como especialização ${ }^{(7)}$.

Em estudo realizado em 1998, constatou-se que $66,1 \%$ dos enfermeiros docentes em quatro instituições de ensino de graduação em Enfermagem da cidade de São Paulo fazem uso das Terapias Alternativas/ Complementares, embora, dos que fazem uso, apenas $58,9 \%$ falam desse assunto com seus alunos ${ }^{(12)}$.

Em recente estudo realizado no Canadá, junto a alunos do último ano dos cursos de graduação em medicina, farmácia, fisioterapia, terapia ocupacional e enfermagem sobre seu conhecimento e opinião a respeito das TAC, os resultados mostram que são os futuros enfermeiros aqueles que mais fazem uso de tais técnicas $(44,7 \%)$ e revelam, com relação ao conhecimento das técnicas, que o toque terapêutico é a mais conhecida pela Enfermagem naquele país ${ }^{(14)}$.

Observa-se que 0 interesse pelas TAC vem crescendo nos últimos anos, constituindo objeto de investigação científica para diversos pesquisadores. Podemos vê-las também, sendo inseridas como conteúdo curricular nos cursos de graduação em enfermagem, quer seja de forma optativa ou obrigatória. Entretanto, pouco ainda se sabe sobre o conhecimento dos alunos desses cursos sobre essa temática, sobre a própria consolidação dessa disciplina e seu desenvolvimento nas Instituições de ensino.

Diante do exposto, perguntamos: será que o acadêmico de Enfermagem está sendo adequadamente preparado para atuar nesse contexto, visto que ainda são poucas as escolas que oferecem disciplina específica nessa área? E será que esses alunos conhecem o fato dessa área constituir especialização profissional reconhecida para a Enfermagem? Essas são questões que nortearam a realização deste estudo.

\section{OBJETIVOS DO ESTUDO}

Tivemos como objetivos neste trabalho:

- discutir o conhecimento, a utilização ou recomendação de terapias alternativas/complementares por acadêmicos de enfermagem de escolas que oferecem esse conteúdo de forma obrigatória ou optativa na grade curricular - verificar se os acadêmicos de enfermagem, de escolas que oferecem as terapias alternativas/complementares como conteúdo obrigatório ou optativo em seu curso, sabem do caráter legal desse tipo de assistência.

\section{MATERIAL E MÉTODO}

- Tipo de estudo: trata-se de estudo exploratório, descritivo, transversal e de campo.

- Local de estudo: o estudo foi realizado em duas instituições de ensino superior de Enfermagem da cidade de São Paulo, uma pública e uma privada, nas quais as TAC integram a grade curricular como disciplina optativa e obrigatória, respectivamente.

- Amostra: 178 alunos regularmente matriculados no curso de graduação responderam a um questionário distribuído de forma eqüitativa, entre alunos das quatro séries. Assim sendo, participaram 48 alunos da primeira série, 41 alunos da segunda série, 48 alunos da terceira série e, finalmente, 41 alunos da quarta série.

- Procedimento de coleta de dados: após a aprovação do projeto por ambas as instituições, a coleta de dados ocorreu durante os meses de agosto, setembro e outubro de 2000, mediante questionário aplicado aos alunos, com prévio esclarecimento e autorização dos mesmos por escrito (consentimento livre e esclarecido). Os alunos foram aleatoriamente escolhidos, obedecendo apenas ao critério da abordagem oportuna.

- Tratamento dos dados: os dados foram analisados por número e porcentagem. Utilizamos a proposta de $\mathrm{Hill}^{(6)}$ para classificar as terapias complementares citadas pelos acadêmicos.

\section{APRESENTAÇÃO DOS RESULTADOS}

Dos 178 (100\%) alunos pesquisados, 159 (89\%) são do sexo feminino e 19 (11\%) são do sexo masculino. A média de idade dos acadêmicos é de 24,3 anos, 
revelando uma amostra de indivíduos jovens. Podemos observar que a porcentagem de homens que escolheram se dedicar à Enfermagem é ainda muito pequena conferindo à profissão um caráter "feminino".

Questionados se conheciam alguma TAC, 157 (88\%) responderam afirmativamente, enquanto 21 (12\%) referiram não conhecer. Com relação às TAC conhecidas pelos alunos, os resultados podem ser vistos na Tabela 1.

Tabela 1 - Relação das TAC conhecidas por acadêmicos de Enfermagem de duas instituições de ensino da cidade de São Paulo. São Paulo, 2001

\begin{tabular}{|c|c|c|}
\hline Grupos e tipos de terapias citadas & $\mathrm{N}$ & $\%$ \\
\hline \multicolumn{3}{|l|}{ Terapias físicas } \\
\hline 1. Acupuntura & 92 & 58 \\
\hline 2.Massagem (não especificada) & 29 & 18 \\
\hline 3.Cristais & 4 & 2,5 \\
\hline 4.Reflexologia & 3 & 2 \\
\hline 5.Shiatsu/Do-In & 4 & 2,5 \\
\hline 6.Quiroprática & 2 & 1,5 \\
\hline \multicolumn{3}{|l|}{ Fitoterapia } \\
\hline 1.Florais & 98 & 62 \\
\hline 2.Fitoterapia & 29 & 18 \\
\hline 4.Aromaterapia & 9 & 6 \\
\hline \multicolumn{3}{|l|}{ Terapias mentais e espirituais } \\
\hline 1.Musicoterapia & 29 & 18 \\
\hline 2.Cromoterapia & 32 & 20 \\
\hline 3.Toque terapêutico & 10 & 6,5 \\
\hline 4.Reiki & 9 & 6 \\
\hline 5.Hipnose & 2 & 1,5 \\
\hline \multicolumn{3}{|l|}{ Hidroterapia } \\
\hline 1.Hidroterapia (não especificada) & 8 & 5 \\
\hline \multicolumn{3}{|l|}{ Concepções globais } \\
\hline 1.Homeopatia & 49 & 31 \\
\hline \multicolumn{3}{|l|}{ Métodos de diagnose } \\
\hline 1.Iridologia & 2 & 1,5 \\
\hline \multicolumn{3}{|l|}{ Nutrição } \\
\hline Terapêutica nutricional ortomolecular & 1 & 0,75 \\
\hline Outros & 21 & 13 \\
\hline
\end{tabular}

Pela análise da Tabela 1, podemos verificar que a TAC mais citada foi a terapia floral (62\%). Logo em seguida vem a acupuntura (58\%). Além dessas, as mais mencionadas foram: a homeopatia (31\%), a cromoterapia (20\%), a fitoterapia, a musicoterapia e massagem (18\%). Onze TAC que não obedecem à classificação citada anteriormente ${ }^{(6)}$ foram referidas, como cirurgia espiritual, medicina natural, equinoterapia e cura prânica. Acreditamos que o fato de ambas as escolas terem grande envolvimento com a terapia floral pode ter contribuído para sua citação destacada, uma vez que a escola pública mantém um curso de especialização e a escola privada conta com consulta de enfermagem, em regime ambulatorial, nessa área.

Ao serem questionados acerca do modo como ficaram conhecendo as TAC, diversas fontes foram mencionadas (em alguns casos mais de uma por aluno), $35(22 \%)$ referiram terem-nas conhecido durante a disciplina de "Terapias Alternativas", 48 (30\%) através de livros, revistas e TV e $43(27 \%)$ através de amigos e familiares. Dezenove alunos (12\%) afirmaram terem-nas conhecido na faculdade, não especificando se durante as aulas, e $10(6 \%)$ através de docentes. Foram ainda citados: médicos, porque as utilizam ou já utilizaram, outras pessoas que as utilizam e no trabalho ( $9 \%)$. Onze alunos (4\%) não responderam essa questão.

Esses achados mostraram que o conhecimento do acadêmico sobre TAC acontece principalmente por meio do senso comum (veículos de comunicação e informações transmitidas verbalmente), uma vez que esse conhecimento faz parte do "saber popular" e não do "saber oficial" do aluno ${ }^{(16)}$. Essa forma de contato com as TAC parece ainda prevalecer sobre o ensino formal, embora poucos alunos da amostra estudada já tivessem cursado ou se encontravam cursando as disciplinas específicas. $\mathrm{Na}$ escola privada, todos os alunos cursam "Enfermagem em Terapias Alternativas" no $3^{\circ}$ ano (dois semestres) e na escola pública cursam "Enfermagem nas Práticas Complementares de Saúde", a partir do quarto semestre, em caráter optativo.

Questionados se já haviam discutido com docentes sobre TAC, a maior parte dos alunos (59\%) referiu nunca ter discutido, enquanto 73 alunos (41\%) responderam afirmativamente. Dos 73 acadêmicos que já haviam discutido esse assunto com docentes, 42 (57,5\%) afirmaram ter discutido várias vezes, $9(12 \%)$ referiram ter discutido apenas 1 vez, 8 (11\%) discutiram 2 vezes, 4 $(5,5 \%)$ não souberam especificar quantas vezes haviam discutido, 5 (7\%) discutiram 3 vezes e 5 (7\%) não responderam a questão. Os alunos que afirmaram já terem discutido sobre TAC com docentes, foram ainda questionados com relação à disciplina envolvida nessa discussão. A disciplina "Terapias Alternativas" foi a mais citada (52 vezes, por $71 \%$ dos acadêmicos). "Saúde Coletiva" foi citada por 3 (4\%), da mesma forma que "Saúde do Adulto" e "Relacionamento Enfermeiro-Paciente". Foram 
citadas 2 vezes (3\%) cada uma das seguintes disciplinas: "Didática", "Psicologia" e "Patologia" e 1 vez cada (1\%): "Pediatria", "Saúde da Mulher", "Iniciação Científica" e "Metodologia de Pesquisa". Três respondentes (4\%) não citaram disciplinas, mas o nome de docentes e 1 (1\%) não respondeu. Podemos perceber que a existência de uma disciplina voltada a essa temática possibilita um fórum maior de discussões sobre o assunto. Embora outras disciplinas tenham sido lembradas, vale ressaltar que quatro daquelas que foram citadas possuíam, em seu quadro, docentes com especialização em alguma terapia alternativa.

Questionados se faziam uso de TAC, 109 alunos $(61 \%)$ referiram não as utilizarem, enquanto $62(35 \%)$ as utilizam, 4 (2,5\%) citaram não fazer uso atualmente, mas já o terem feito e $1(0,5 \%)$ refere não fazer uso, mas que gostaria de fazê-lo. Dois alunos (1\%) não responderam essa questão.

As TAC utilizadas pelos 62 alunos são descritas na Tabela 2.

Tabela 2 - Relação das Terapias Alternativas/ Complementares utilizadas por acadêmicos de Enfermagem de duas instituições de ensino da cidade de São Paulo. São Paulo, 2001

\begin{tabular}{lcc}
\hline Terapias Utilizadas* & $\mathrm{n}$ & $\%$ \\
\hline Florais & 24 & 39 \\
Fitoterapia & 16 & 25 \\
Homeopatia & 16 & 25 \\
Acupuntura & 9 & 14,5 \\
Massagem & 6 & 10 \\
Shiatsu/Do-In & 6 & 10 \\
Hidroterapia & 3 & 5 \\
Musicoterapia & 3 & 5 \\
Reiki & 2 & 3 \\
Cromoterapia & 2 & 3 \\
Nutrição & 1 & 1,5 \\
Yoga & 1 & 1,5 \\
RPG & 1 & 1,5 \\
\hline
\end{tabular}

* Parte dos graduandos citou o uso de mais de uma técnica

Verificamos que a TAC mais utilizada é a terapia floral (39\%), logo seguida pela fitoterapia e homeopatia (25\%). Acreditamos mais uma vez que a terapia floral foi a mais indicada pelo fato dos alunos poderem consultar docentes especializados que ambas as instituições de ensino dispõem.

Ao serem questionados se haviam observado resultado com o uso de TAC, não especificando se esse uso era feito pelo aluno ou por outras pessoas, 71 (40\%) responderam afirmativamente, enquanto 51 (29\%) referiram não ter observado resultados. Cinqüenta e seis alunos (31\%) não responderam essa questão. Com relação ao resultado observado, 31 (44\%) dos alunos respondentes referiram ter notado melhora nos sintomas/saúde. Dezesseis (22,5\%) referiram melhora da tensão/ ansiedade/depressão/desânimo, 15 (21\%) citaram que houve alívio de dores e $4(5 \%)$ referiram equilíbrio como resultado observado. Relaxamento, bem-estar, melhora do estado psicoespiritual, aumento do autocontrole e da autoconfiança e terapias específicas foram citados 5 (7\%) vezes e sono tranqüilo foi citado por $2(3 \%)$ alunos. Alguns acadêmicos citaram, também, mais de um resultado observado.

Os alunos foram também questionados se recomendariam o uso de TAC. Cento e cinqüenta e dois alunos (85\%) afirmaram recomendar seu uso, 18 (10\%) não o recomenda e $8(5 \%)$ não responderam a questão. Embora muitos alunos não façam uso de nenhuma técnica alternativa/complementar, a grande maioria a recomenda. As justificativas dos acadêmicos que recomendariam o uso de TAC para a indicação da utilização de tais técnicas podem ser observadas na Tabela 3.

Tabela 3 - Relação das justificativas dos acadêmicos de enfermagem de duas instituições de ensino da cidade de São Paulo para a indicação do uso de terapias alternativas/ complementares. São Paulo, 2001

\begin{tabular}{lcc}
\hline Justificativas* & $\mathrm{n}$ & $\%$ \\
\hline $\begin{array}{l}\text { Acreditam na eficácia das TAC e vivenciaram } \\
\text { bons resultados com seu uso }\end{array}$ & 90 & 62 \\
$\begin{array}{l}\text { Toda forma de tratamento é válida e deve ser } \\
\text { "experimentada" }\end{array}$ & 6 & 4 \\
$\begin{array}{l}\text { As TAC são menos agressivas ao organismo do } \\
\text { que a alopatia }\end{array}$ & 9 & 6 \\
$\begin{array}{l}\text { Devem ser utilizadas apenas como } \\
\text { complemento à alopatia }\end{array}$ & 13 & 9 \\
$\begin{array}{l}\text { Seu uso é importante pois trata o indivíduo } \\
\text { como um todo }\end{array}$ & 8 & 5,5 \\
$\begin{array}{l}\text { Indicaram terapias específicas } \\
\text { Não justificaram o porquê da indicação do uso } \\
\text { de TAC }\end{array}$ & 4 & 15 \\
\hline
\end{tabular}

* Parte dos entrevistados citou mais de uma justificativa

Interessante notar que a principal justificativa apresentada pelos acadêmicos para indicação das TAC está baseada na crença sobre sua eficácia e na experiência pessoal. Nenhum aluno mencionou o caráter científico das TAC, na atualidade, e que deveriam ser a primeira justificativa de escolha para a indicação de qualquer uma delas, conferindo, portanto, a profissionalização do cuidado. Se o conhecimento das TAC, como vimos anteriormente, é obtido, na maioria das vezes, fora do meio acadêmico, a sua indicação profissional não pode estar pautada apenas no bom senso e sim em bases científicas cada vez mais sólidas, como 
é esperado para qualquer outra intervenção de enfermagem prescrita pelo enfermeiro. Já dispomos de vasta literatura sobre algumas TAC que respaldam cientificamente sua utilização na área da saúde e na medicina convencional. A acupuntura, por exemplo, há alguns anos execrada pela categoria médica, vem sendo reivindicada como ato médico, numa tentativa de subtrair de outros profissionais da saúde a sua prática legítima e aprovada pelos conselhos que regulam o exercício profissional, como é o caso do Conselho Federal de Enfermagem. Estudos em terapia floral e musicoterapia, entre outros, vêm sendo desenvolvidos em nosso meio e, embora a pesquisa seja incipiente, os resultados apontam um caminho promissor. As TAC, de modo geral, precisam ser mais bem pesquisadas para que, de fato, possam ser conhecidos seus limites e seus reais benefícios otimizando-as na assistência à saúde humana. Observamos, ainda, que quinze alunos responderam que recomendariam as TAC, sem sequer saberem o porquê, uma vez que não apresentaram justificativas para sua indicação e isso é preocupante. Isso ressalta, mais uma vez, que as TAC devem ser amplamente discutidas e investigadas, a fim de que suas indicações sejam mais precisas e realizadas de forma consciente e competente pelos enfermeiros.

Questionados se o enfermeiro poderia ser especialista em TAC, a maioria (168 alunos, ou seja, 94\% dos acadêmicos) respondeu afirmativamente, enquanto apenas $2(1 \%)$ negaram essa possibilidade. Oito alunos (5\%) deixaram a questão em branco.

Os acadêmicos foram solicitados a justificar o porquê da possibilidade de especialização em TAC para o enfermeiro, e a resposta esperada (que a especialização é possível por seu caráter legal, pela existência de cursos registrados e reconhecidos pelo órgão que fiscaliza a profissão) foi citada por apenas 10 alunos (6\%). Esse dado aponta para o desconhecimento que os alunos têm sobre o caráter legal da especialização, mesmo que o dobro desse achado tenha recebido essa informação durante as aulas sobre TAC, o que reforça a idéia de que maior ênfase deva ser dada a esse assunto, pois o enfermeiro deve dominar os aspectos éticos e legais de suas ações.

Foram citados ainda pelos alunos como justificativa: $42(25 \%)$ responderam ser possível a especialização, pois o enfermeiro pode aprofundar-se no tema estudando, 23 (14\%) alegaram que a especialização em TAC é uma forma de cuidar, que é função do enfermeiro, 68 (41\%) responderam valorizando as TAC ou afirmando saber de sua importância e de seu crescimento na atualidade e 23 (14\%) não souberam justificar sua resposta.

\section{CONCLUSÕES E CONSIDERAÇÕES FINAIS}

Pudemos verificar neste estudo, diante dos objetivos propostos, que o conhecimento do acadêmico de enfermagem sobre TAC nas instituições de ensino onde o tema é abordado de forma obrigatória ou optativa durante a graduação é obtido ainda, principalmente, pelo senso comum, ou seja, extramuros acadêmicos.

As essências florais é a terapia mais conhecida pelos alunos, provavelmente porque as instituições de ensino têm atuação específica nessa área.

Com relação ao uso de TAC pelos acadêmicos, verificamos que a maioria recomenda sua utilização, principalmente pela crença na sua eficácia e vivência de bons resultados com seu uso, embora apenas uma pequena parcela as utilize.

Chamou-nos a atenção o desconhecimento dos alunos sobre o respaldo legal da especialização para o enfermeiro. A orientação nesse sentido nos parece ainda insuficiente, o que aguça a atenção, pois, se os acadêmicos não sabem sobre seus direitos, talvez também não estejam plenamente conscientes sobre seus deveres profissionais.

É urgente e necessário o esclarecimento a esses acadêmicos, feito por meio de seus docentes, que, caso não estejam corretamente informados, devem nutrir maior interesse por cursos de atualização. Não se pode admitir que as TAC, por serem ainda de domínio de poucos docentes, venha a restringir a formação dos alunos, uma vez que todas as disciplinas da grade curricular estão envolvidas nesse processo. Questionamos ainda, uma vez que as TAC já são realidade no contexto profissional, como estarão sendo discutidas em instituições de ensino que não a prevêem como disciplina optativa ou obrigatória em seus currículos. Afinal, como será possível lutarmos pela participação do enfermeiro no mercado de trabalho dos terapeutas alternativos se estamos formando enfermeiros que efetivamente não sabem que esse mercado legalmente Ihes pertence? Ou, ainda, como iremos incorporar as TAC no cuidado de enfermagem se o enfermeiro não possuir o conhecimento necessário para sua implementação? 


\section{REFERÊNCIAS BIBLIOGRÁFICAS}

1. Landmann J. As medicinas alternativas: mito, embuste ou ciência ? - homeopatia, medicina herbal, acupuntura, meditação, ioga, biofeedback e cura pela fé. Rio de Janeiro (RJ): Guanabara; 1989.

2. Capra F. O ponto de mutação. São Paulo (SP): Cultrix; 1982. 3. Gerber R. Medicina Vibracional : uma medicina para o futuro.São Paulo (SP): Cultrix; 1988.

4. Souza D, Silva M J P da. O holismo espiritualista como referencial teórico para o enfermeiro. Rev Esc Enfermagem USP 1992 agosto; 26(2):235-42, 70-2.

5. Organization Mundial de la Salud. Promoción y desarrollo de la medicina tradicional: informe de una reunión de la OMS. Genebra; 1978.

6. Hill A. Guia das medicinas alternativas: todos os sistemas de cura natural. São Paulo (SP): Hemus.

7. Barbosa MA. A utilização de terapias alternativas por enfermeiros brasileiros. [Tese]. São Paulo (SP): Escola de Enfermagem/USP; 1994.

8. Falcão D. Hospitais se rendem às terapias "alternativas". Folha de São Paulo 2000 Maio 11: Suplemento Folha Equilíbrio, 10-2.

9. Nogueira MJ de C. Fitoterapia e enfermagem comunitária. [Tese]. São Paulo (SP): Escola de Enfermagem/USP; 1983. 10. Conselho Federal de Enfermagem (BR). Parecer normativo do COFEN n 004/95. Dispõe sobre as atividades em Terapia alternativa. Bol Inf COREn 1995; 18(4):8.

11. Conselho Federal de Enfermagem. (BR). Resolução COFEN 197. Estabelece e reconhece as Terapias Alternativas como especialidade e/ou qualificação do profissional de Enfermagem. In: Conselho Regional de Enfermagem. Documentos básicos de enfermagem. São Paulo (SP); 1997. 12. Silva MJP da, Benko MA. O uso da terapias alternativas por enfermeiros docentes. Rev Bras Enfermagem 1998 julhosetembro; 5(3):457-68.

13. Trovo MM, Silva MJP da. Terapias alternativas/ complementares - a visão do graduando de Enfermagem. Rev Esc Enfermagem USP 2002 março; 36(1):80-7.

14. Baugniet J, Bonn H, Ostbye T. Complementary/Alternative Medicine: comparing the view of medical students in other health care professions. Fam Med 2000 março; 32(3):17884.

15. Reed FC, Pettigrew, AC, King MO. Alternative and Complementary Therapies in Nursing Curricula. J Nurs Educ 2000 março; 39(3):133-9.

16. Nogueira MJ de C. Terapêuticas alternativas na enfermagem: por que não? Enfoque 1983; 11(2):30-5. 